\title{
Seroprevalence and associated factors of HSV-2 infection among general population in Shandong Province, China
}

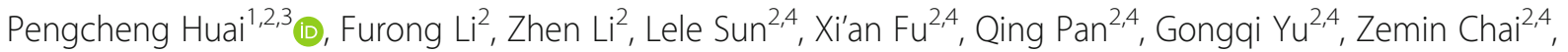
Tongsheng Chu' ${ }^{2}$, Zihao Mi $i^{2,4}$, Fangfang Bao ${ }^{2,4}$, Honglei Wang ${ }^{2,4}$, Bingni Zhou ${ }^{2,4}$, Chuan Wang ${ }^{2,4}$, Yonghu Sun ${ }^{2,4}$, Guive $\mathrm{Niu}^{2,4}$, Yuan Zhang ${ }^{2,4}$, Fanghui Fu ${ }^{2,4}$, Xiaogiao Lang ${ }^{2,4}$, Xiaoling Wang ${ }^{2,4}$, Hui Zhao ${ }^{2,4}$, Daina Liu ${ }^{2,4}$,

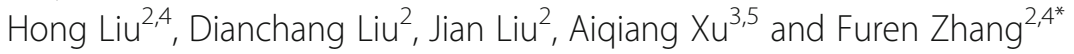

\begin{abstract}
Background: Herpes simplex virus type-2 (HSV-2) infection is the main cause of genital ulcer disease and increases the risk of HIV acquisition. Little information is available regards the epidemiological characteristics of HSV-2 among general population in China. The aim of this study was to explore seroprevalence and associated factors of HSV-2 and provide information for design of HSV-2 control strategy in Shandong, China.

Methods: In this cross-sectional study, a total of 8074 persons, 18-49 years of age, were selected using multi-stage probability sampling to represent the general population of Shandong in 2016. Demographic data were collected through face-to-face interviews. Other variables were obtained by self-administered questionnaire surveys. Blood was collected for HSV-2 IgG detection with ELISA.
\end{abstract}

Results: A total of 7256 sexually-active participants were included in the analysis. The weighted seroprevalence of HSV-2 infection was 4.2\% (95\% confidence interval [Cl], 3.2-5.3) in females, which was significant higher than that in males $(2.7 \% ; 95 \% \mathrm{Cl}, 1.1-4.2)(P=0.04)$. The seroprevalence of HSV-2 was higher in individuals from eastern region (6.4\%; 95\% Cl, 5.9-6.9) and urban areas (4.3\%; 95\% Cl, 2.6-6.0) of Shandong than those from other regions $(P<0.01)$. Associated factors for HSV-2 infection among men were being urban residents (adjusted odds ratio [AOR], 2.36; 95\% $\mathrm{Cl}, 1.14-4.88$ ), having two or more sex partners in the past year (AOR, 3.22; 95\% Cl, 1.90-5.43) and having commercial sex (AOR, 1.51; 95\% Cl, 1.00-2.26). Among females, being divorced or widowed (AOR, 1.79; 95\% Cl, 1. 08-2.97), having a tattoo (AOR, 2.89; 95\% Cl, 1.07-7.84), and being dissatisfied with the sex activity quality (AOR, 2. $12 ; 95 \% \mathrm{Cl}, 1.24-3.63)$ was associated with HSV-2 infection.

Conclusions: This study showed a relatively low burden of HSV-2 in Shandong province, China compared with the seroprevalence reported in many other provinces and countries. HSV-2 control programs in Shandong should focus on eastern, urban and female residents, and pay more attention to individuals with identified associated factors.

Keywords: HSV-2 (herpes simplex virus type-2), Seroprevalence, Associated factors, China

\footnotetext{
* Correspondence: zhangfuren@hotmail.com

${ }^{2}$ Shandong Provincial Institute of Dermatology and Venereology, Shandong

Academy of Medical Sciences, 27397 Jingshi Road, Jinan 250022, China

${ }^{4}$ Shandong Provincial Key Laboratory for Dermatovenereology, Jinan, China

Full list of author information is available at the end of the article
}

(c) The Author(s). 2019 Open Access This article is distributed under the terms of the Creative Commons Attribution 4.0 International License (http://creativecommons.org/licenses/by/4.0/), which permits unrestricted use, distribution, and reproduction in any medium, provided you give appropriate credit to the original author(s) and the source, provide a link to the Creative Commons license, and indicate if changes were made. The Creative Commons Public Domain Dedication waiver (http://creativecommons.org/publicdomain/zero/1.0/) applies to the data made available in this article, unless otherwise stated. 


\section{Background}

Herpes simplex virus type-2 (HSV-2) infection is the main cause of genital ulcer disease worldwide [1]. In 2012, the estimated prevalence of HSV-2 among individuals 15-49 years of age was $11.3 \%$, corresponding to 417 million infected cases in the word [2]. Approximately $88 \%$ of HSV-2 infected patients do not know they have the disease, but the asymptomatic nature of genital herpes facilitates the spread of the infection in the general population $[3,4]$. The infection can be transmitted to the fetus during pregnancy, which is an important cause of neonatal herpes, death, and long-term disability [5]. In addition, HSV-2 increases the risk of HIV acquisition by 1.7 fold in men and 2.1 fold in women, and the risk is even higher in newly HSV-2 infected individuals $[2,6]$.

Syphilis and HIV have increased significantly in China from 2004 to 2013, with annual percentage changes of $16.3 \%$ for both diseases [7]. However, little information is available regards the prevalence or incidence of HSV-2 among the general population in China. A population-based survey provided an estimate of seroprevalence and associated factors, which facilitated the design of specific HSV-2 control program [8]. To our knowledge, only two studies estimated seroprevalence of HSV-2 infection among general population in China. The first survey was conducted in Zhejiang Province in 2006; but the participants did not include an urban population [9]. Another study conducted in Shanghai in 2011, which reported the seroprevalence of HSV-2 among 600 female residents; however, no males were included in this study [10]. Thus, it is essential to conduct a population-based study with a large sample size including males and females to determine the urban and rural seroprevalence of HSV-2 among the general population in China.

Since the implementation of the Chinese universal two-child policy in 2015, Chinese couples have had the freedom to have a second child [11]. More HSV-2 infected asymptomatic females who want to have their second baby may suffer from adverse complications. Therefore, targeted propaganda and education or other specific control interventions are needed to prevent HSV-2 infections and adverse outcomes among hish risk individuals before they got pregnant.

This study was conducted to estimate the seroprevalence and associated factors of HSV-2 and provide information for design of HSV-2 control strategy in Shandong Province.

\section{Methods}

\section{Study design and participants}

This population-based, cross-sectional study was conducted between May and August 2016. Details of the study design have been described previously [12]. A multi-stage complex sampling method was used to select participants who could represent the general population 18-49 years of age in Shandong Province, China. Shandong is a peninsular province located in eastern China. The population of Shandong was 98,470,000 in 2015, accounting for approximately $7 \%$ of the whole population in China. Shandong was divided into east, northwest, south, and middle based on geographic region; 12 urban districts or counties (primary sampling units [PSUs]) were selected randomly from the four strata. The selection of rural townships or urban street districts (subunits) from the PSUs and selection of rural villages or urban communities from subunits used the probability proportionate to size sampling (PPS) method. PPS method is often uesd in muti-stage complex sampling and the probability of selection for a unit is directly proportional to its size. While in proportional allocation, the probability of selection for a unit is the same for all strata. Rural villages and urban communities were selected at a proportion of 1:1. A total of 184 villages and 183 communities were included. Systematic sampling based on age and gender distribution of Shandong was conducted to select individuals from residents 18-49 years of age who had lived in the current residence for at least the past 6 months. Thus, 22 individuals were extracted from each village or community based on the sample size and number of selected villages or communities.

Inclusion criteria were as follows: 18-49 years of age by 31 September 2015; continuous residence at the study site for at least the past 6 months. Exclusion criteria were as follows: individuals who had not had their sexual debut; and could not provide correct information due to mental illness or intoxication.

The study was approved by the Ethics Committee of Shandong Provincial Institute of Dermatology and Venereology (approval number: 2016-04). Individuals who were willing to provide blood and answer pertinent questions were recruited in this study. Before each interview, oral informed consent was obtained from the participant.

\section{Procedures}

Three training days were provided to the fieldwork staff in each of the PSUs. Each field team included one laboratory technician for blood collection, two questionnaire interviewers, and one financial staff for distribution of the interview allowance. In addition, one trained supervisor from the research group was also designated to each field team for informed consent and quality control.

We performed the investigation in a village/community clinic or meeting room of the village/community committee. Demographic information, including sex, age, marriage (unmarried, married, divorced, or 
widowed), and rural or urban residence, was collected by face-to-face interview. Other information was completed by the participants themselves. To increase the response rate, investigations were usually performed early in the morning or late in the evening because many individuals work during the day. The supervisor in each field team checked the questionnaires for missing value and logical error and wrote a unique alphanumeric code on each questionnaire after the interview.

Five milliliters of venous blood was collected from each participant by a skilled laboratory technician. Blood was put in a styrofoam cooler and transported to the local laboratory within $3 \mathrm{~h}$. Serum was separated from blood and frozen at $-20^{\circ} \mathrm{C}$ upon receipt of the specimen. Serum was put in the styrofoam cooler and transported to the laboratory at Shandong Provincial Institute of Dermatology and Venereology within 2 weeks.

We tested serum for HSV-2 using an enzyme-linked immune sorbent assay (ELISA) for IgG antibodies. According to the manufacturer instructions, the sensitivity, specificity, false positive rate and false negative rate of this test were 97.3, 98.1, 1.9 and $2.7 \%$ respectively. Result was valid when optical density (OD) value of positive control $\geq 1.00$, OD value of negative control $\leq 0.05$, and OD value of cut-off control $\geq 0.15$ for each test. OD value of sample more than that of cut-off control was deemed positive. Many other population-based studies on HSV-2 seroprevalence used the same method [3, 13]. Individuals with positive tests results were referred to a local STI clinic, genitourinary clinic, or general hospital for treatment.

\section{Operational definition}

The self-designed structured questionnaires included variables on tattooing, smoking (smokers defined as those who had smoked 100 or more cigarettes during lifetime), times of drunk in the past 12 months $(0,1-3$, $4-6$, and $>6$ ), domestic violence, history of sexually transmitted infections (STIs) in the past 5 years, quality of sex activity (subjective satisfied or not satisfied), sexual behaviors, such as age at sexual debut $(\leq 20$ years and $>20$ years), extramarital sex, commercial sex and number of sex partners ( 1 and $\geq 2$ ).

\section{Statistical analysis}

All survey data were double-entered into Epidata 3.1 (EpiData association, Odense, Denmark). We analyzed data using surveyfreq and surveylogistic methods (SAS 9.3; SAS Institute Inc., Cary, NC, USA). The seroprevalence of HSV-2 was estimated with application of selection probability, non-response, and post-stratification weights. The $95 \%$ confidence interval (CI) for the seroprevalence of STIs was calculated based on total population weights and Taylor series linearization. Independent associations between potential associated factors and HSV-2 infection were explored with logistic regression and reported as the crude odds ratio (COR) in bivariate analysis. For multivariate logistic regression model analysis, associated factors with a $P$ value $<0.10$ in bivariate analysis, as well as age, were included in the model [14]. Adjusted ORs (AOR) and 95\% CIs were presented. In addition, the variance inflation factor, condition index, and variance proportions were calculated to examine potential collinearity. All statistical tests were two-sided, and variables with $P$-value $<0.05$ were considered statistically significant.

\section{Results}

Of the 8074 individuals originally sampled, 189 were removed because of mental illness or not available, 231 individuals declined to take part in the study, and 391 had not had their sexual debut. Thus, 7263 (90.0\%) individuals completed the survey and provided blood samples. Seven invalid blood samples were excluded, leaving 7256 (89.9\%) qualified blood samples with test results included in the analysis (Fig. 1).

\section{Seroprevalence of HSV-2}

The weighted age, gender and region-specific seroprevalence of HSV-2 is shown in Table 1. Of the 7256 blood samples tested, 254 participants (88 males and 166 females) tested positive for HSV-2. The estimated seroprevalence of HSV-2 in the general population 18-49 years of age in 2016 was $3.4 \%$ (95\% CI, 2.2-4.7), 2.7\% (95\% CI, 1.1-4.2) for males, and 4.2\% (95\% CI, 3.2-5.3)

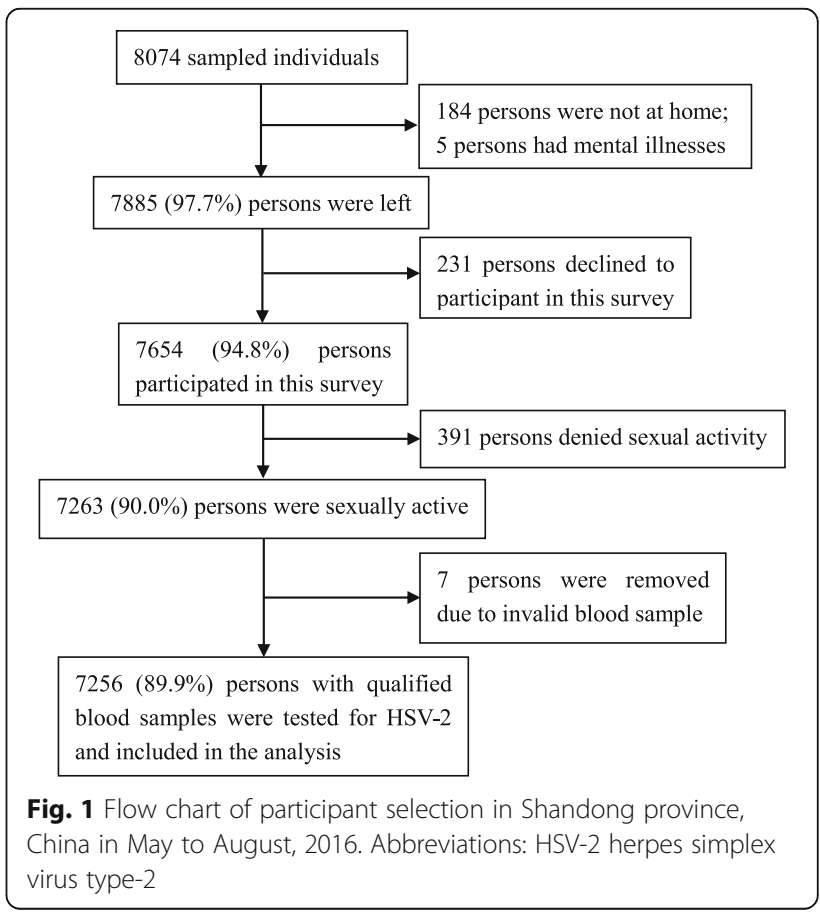


Table 1 The weighted seroprevalence of HSV-2 in participants 18-49years of age by gender, age group and region in Shandong province, China in May to August, 2016

\begin{tabular}{|c|c|c|c|c|}
\hline & \multirow{2}{*}{$\begin{array}{l}\text { Male } \\
{[\mathrm{n}, \%(95 \% \mathrm{Cl})]}\end{array}$} & \multirow{2}{*}{$\begin{array}{l}\text { Female } \\
{[\mathrm{n}, \%(95 \% \mathrm{Cl})]}\end{array}$} & \multicolumn{2}{|c|}{ Denominator $^{a}$ (unweighted, weighted $^{b}$ ) } \\
\hline & & & Male & Female \\
\hline \multicolumn{5}{|l|}{ Age (years) } \\
\hline $18-24$ & $6,2.4 \%(0.0-5.9)$ & $9,3.2 \%(0.9-5.4)$ & 253,852 & 195,828 \\
\hline $25-29$ & $12,1.4 \%(0.5-2.3)$ & $31,3.1 \%(2.2-4.0)$ & 786,500 & 914,499 \\
\hline $30-34$ & $10,2.5 \%(0.0-5.2)$ & $33,6.9 \%(5.0-8.8)$ & 503,471 & 559,465 \\
\hline $35-39$ & $19,3.6 \%(1.4-5.8)$ & $29,4.6 \%(2.9-6.3)$ & 566,575 & 591,561 \\
\hline $40-44$ & $27,3.6 \%(1.7-5.6)$ & $36,4.7 \%(2.1-7.4)$ & 721,675 & 742,668 \\
\hline $45-49$ & $14,2.3 \%(0.0-4.7)$ & $28,3.5 \%(2.0-5.1)$ & 697,578 & 729,584 \\
\hline \multicolumn{5}{|l|}{ Region } \\
\hline Northwest & $6,1.4 \%(1.0-1.8)$ & $10,2.6 \%(0.7-4.6)$ & 340,393 & 349,358 \\
\hline Middle & $14,1.4 \%(1.2-1.6)$ & $33,2.9 \%(1.9-4.0)$ & 902,949 & 916,861 \\
\hline South & $28,1.8 \%(1.3-2.3)$ & $63,3.9 \%(2.5-5.4)$ & 1505,1469 & 1582,1493 \\
\hline East & $40,6.2 \%(5.2-7.3)$ & $60,6.5 \%(5.1-8.0)$ & 779,840 & 883,893 \\
\hline Total & $88,2.7 \%(1.1-4.2)$ & $166,4.2 \%(3.2-5.3)$ & 3526,3651 & 3730,3605 \\
\hline
\end{tabular}

Abbreviations: $\mathrm{Cl}$ confidence interval

${ }^{a}$ Denominator was participants with sex experience and a blood test result

${ }^{b}$ Selection probability weighting, non-response weighting, and post-stratification weighting were applied to calculate the weighted denominator

for females, corresponding to $\sim 1,735,000$ total cases (95\% CI, 1,058,000-2,411,000) who had been infected with HSV-2 in Shandong. The HSV-2 seroprevalence for females was significantly higher than males $(P=0.04)$. The highest seroprevalence of HSV-2 for males was in males 35-44 years of age (3.6\%; 95\% CI, 2.5-4.8). For females, the highest seroprevalence of HSV-2 was in those $30-34$ years of age $(6.9 \%$; $95 \%$ CI, $5.0-8.8)$. The seroprevalence of HSV-2 was higher in males $(6.2 \%$; $95 \%$ CI, 5.2-7.3) and females (6.5\%; 95\% CI, 5.1-8.0) from Eastern region of Shandong $(6.4 \%$; 95\% CI, 5.9-6.9) than those from other regions $(P<0.01$ for both genders). The seroprevalence of HSV-2 for urban residents was 4.3\% (95\% CI, 2.6-6.0), which was significantly higher than rural residents $2.4 \%$ (95\% CI, 1.9-2.8, $P<0.01$ ).

\section{Associated factors for HSV-2 infection}

With respect to males, bivariate analyses showed that the HSV-2 seroprevalence was higher for the following: urban residents; those who smoking; those who had imposed domestic violence on their spouses; those with a transfusion history; those who had engaged in extramarital or commercial sex; and those who had $>2$ sex partners in the past year (Table 2).

With respect to females, bivariate analyses indicated that increased HSV-2 seroprevalence was associated with being divorced or widowed, having a tattoo, being dissatisfied with the quality of their sex activity, and having $>2$ lifetime sex partners (Table 3 ).

Based on multivariate analyses, factors remaining significantly associated with HSV-2 infection for males were urban residence (AOR, 2.36; 95\% CI, 1.14-4.88), having $>2$ lifetime sex partners (AOR, 3.22; 95\% CI, 1.90-5.43) and having commercial sex (AOR, 1.51; 95\% CI, 1.00-2.26; Table 2). For females, being divorced or widowed (AOR, 1.79; 95\% CI, 1.08-2.97), having a tattoo (AOR, 2.89; 95\% CI, 1.07-7.84), and being dissatisfied with the quality of one's sex activity (AOR, 2.12; 95\% CI, 1.24-3.63) remained significantly associated with HSV-2 infections (Table 3).

Based on the collinearity diagnosis, the maximal variance inflation factor was 1.15 and the maximal condition index was 1.48 for the male regression model, while the maximal variance inflation factor was 1.02 and the maximal condition index was 1.17 for the female regression model, which indicated no multi-collinearity based on the multivariate logistic analysis.

\section{Discussion}

To our knowledge, this is the first study with a large sample size to determine the seroprevalence and associated factors for HSV-2 among general populations in Shandong Province, China. Overall, the weighted seroprevalence of HSV-2 for females 18-49 years of age was significantly higher than that for males in this study. HSV-2 infection was more prevalent among people from urban and eastern region of Shandong. In addition, associated factors of HSV-2 infection were also identified for both genders. These findings were valuable for design HSV-2 prevention and control intervention in Shandong province. 
Table 2 Associated factors for HSV-2 among men 18-49 years of age in Shandong province, China in May to August, 2016

\begin{tabular}{|c|c|c|c|c|}
\hline & $\%(95 \% \mathrm{Cl})$ & $\begin{array}{l}\text { Crude } \\
\text { OR (95\% Cl) }\end{array}$ & $\begin{array}{l}\text { Adjusted } \\
\text { OR }(95 \% \mathrm{Cl})^{\mathrm{a}}\end{array}$ & Denominator ${ }^{\mathrm{b}}$ unweighted, weighted \\
\hline All ages & $2.7 \%(1.1-4.3)$ & - & - & 3526,3651 \\
\hline Age (years) & - & $p=0.41$ & $p=0.14$ & - \\
\hline $18-24$ & $2.4 \%(0.0-5.9)$ & 1.00 & 1.00 & 253,852 \\
\hline $25-29$ & $1.4 \%(0.5-2.3)$ & $0.59(0.22-1.57)$ & $0.74(0.26-2.10)$ & 786,500 \\
\hline $30-34$ & $2.5 \%(0.0-5.2)$ & $1.06(0.53-2.12)$ & $1.42(0.70-2.89)$ & 503,471 \\
\hline $35-39$ & $3.6 \%(1.4-5.8)$ & $1.56(0.27-8.91)$ & $2.17(0.33-14.11)$ & 566,575 \\
\hline $40-44$ & $3.6 \%(1.7-5.6)$ & $1.56(0.50-4.83)$ & $2.19(0.66-7.28)$ & 721,675 \\
\hline $45-49$ & $2.3 \%(0.0-4.7)$ & $0.98(0.46-2.08)$ & $1.39(0.63-3.05)$ & 697,578 \\
\hline Marital status & & $p=0.92$ & - & \\
\hline Unmarried/married & $2.7 \%(1.0-4.3)$ & 1.00 & - & 3473,3602 \\
\hline Divorced/widowed & $2.4 \%(0.0-6.7)$ & $0.91(0.16-5.13)$ & - & 53,49 \\
\hline Location of residence & - & $p=0.02$ & $p=0.02$ & - \\
\hline Rural & $1.5 \%(0.7-2.3)$ & 1.00 & 1 & 1799, 2082 \\
\hline Urban & $3.6 \%(1.3-5.8)$ & $2.44(1.12-5.26)$ & $2.36(1.14-4.88)$ & 1727,1569 \\
\hline Smoking & & $p=0.08$ & $p=0.14$ & - \\
\hline No & $2.2 \%(0.5-4.0)$ & 1.00 & 1 & 1761,1796 \\
\hline Yes & $3.1 \%(0.0-5.2)$ & $1.39(0.96-2.04)$ & $1.34(0.91-1.99)$ & 1765,1855 \\
\hline Times of drunk in the past year & & $p=0.68$ & - & - \\
\hline 0 & $3.1 \%(0.0-7.0)$ & 1.00 & - & 1042,1058 \\
\hline $1-3$ & $2.0 \%(1.3-2.7)$ & $0.62(0.18-2.08)$ & - & 1049,1073 \\
\hline $4-6$ & $3.2 \%(1.5-4.9)$ & $1.03(0.36-2.94)$ & - & 289,329 \\
\hline$>6$ & $2.0 \%(0.0-3.9)$ & $0.62(0.11-3.42)$ & - & 317,339 \\
\hline Domestic violence to wife ${ }^{c}$ & - & $p<0.01$ & - & - \\
\hline No & $2.4 \%(1.2-3.7)$ & 1.00 & - & 2928,2845 \\
\hline Yes & $4.9 \%(1.0-8.8)$ & $2.06(1.35-3.14)$ & - & 318,275 \\
\hline Transfusion history & - & $p=0.05$ & $p=0.15$ & - \\
\hline No & $2.6 \%(1.0-4.1)$ & 1.00 & 1.00 & 3364,3481 \\
\hline Yes & $5.1 \%(0.6-9.5)$ & $2.03(1.01-4.09)$ & $1.61(0.85-3.07)$ & 162,170 \\
\hline Quality of sex activity & & $p=0.59$ & - & - \\
\hline Satisfied & $2.7 \%(0.9-4.6)$ & 1.00 & - & 3238,3386 \\
\hline Dissatisfied & $2.0 \%(0.6-3.5)$ & $0.73(0.24-2.27)$ & - & 288,266 \\
\hline Extramarital sex ${ }^{c}$ & - & $p<0.01$ & - & - \\
\hline No & $2.4 \%(1.0-3.8)$ & 1.00 & - & 2926,2794 \\
\hline Yes & $4.6 \%(2.6-6.5)$ & $1.93(1.53-2.45)$ & - & 320,326 \\
\hline Number of sex partners in the past year & - & $p<0.01$ & $p<0.01$ & - \\
\hline$<2$ & $2.3 \%(0.9-3.6)$ & 1.00 & 1.00 & 3302,3349 \\
\hline$\geq 2$ & $7.1 \%(1.5-12.7)$ & $3.28(2.05-5.27)$ & $3.22(1.90-5.43)$ & 224,302 \\
\hline Commercial sex & - & $p<0.01$ & $p=0.05$ & - \\
\hline No & $2.5 \%(1.0-4.0)$ & 1.00 & 1.00 & 3382,3463 \\
\hline Yes & $6.3 \%(0.8-11.9)$ & $2.66(1.65-4.29)$ & $1.51(1.00-2.26)$ & 144,188 \\
\hline
\end{tabular}

Cl confidence interval, $O R$ odds ratio

${ }^{a}$ Adjusted for age, location of residence, smoking, transfusion history, number of sex partners in the past year, and commercial sex

${ }^{b}$ Denominator was participants with sex experience and a blood test result

c Those variables were not included into multivariate analyses because of missing data for unmarried participants 
Table 3 Associated factors for HSV-2 among women 18-49 years of age in Shandong province, China in May to August, 2016

\begin{tabular}{|c|c|c|c|c|}
\hline & $\%(95 \% \mathrm{Cl})$ & $\begin{array}{l}\text { Crude } \\
\text { OR }(95 \% \text { Cl) }\end{array}$ & $\begin{array}{l}\text { Adjusted } \\
\text { OR }(95 \% \mathrm{Cl})^{\mathrm{a}}\end{array}$ & $\begin{array}{l}\text { Denominator } \\
\text { unweighted, weighted }\end{array}$ \\
\hline All ages & $4.2 \%(3.2-5.3)$ & - & - & 3730,3605 \\
\hline Age (years) & - & $p=0.57$ & $p=0.59$ & - \\
\hline $18-24$ & $3.2 \%(0.9-5.4)$ & 1.00 & 1.00 & 195,828 \\
\hline $25-29$ & $3.1 \%(2.2-4.0)$ & $0.98(0.51-1.88)$ & $1.04(0.51-2.14)$ & 914,499 \\
\hline $30-34$ & $6.9 \%(5.0-8.8)$ & $2.27(0.99-5.22)$ & $2.46(0.94-6.44)$ & 559,465 \\
\hline $35-39$ & $4.6 \%(2.9-6.3)$ & $1.48(0.74-2.95)$ & $1.61(0.68-3.80)$ & 591,561 \\
\hline $40-44$ & $4.7 \%(2.1-7.4)$ & $1.52(0.59-3.94)$ & $1.62(0.55-4.79)$ & 742,668 \\
\hline $45-49$ & $3.5 \%(2.0-5.1)$ & $1.13(0.44-2.89)$ & $1.18(0.38-3.63)$ & 729,584 \\
\hline Marital status & - & $p=0.01$ & $p=0.02$ & - \\
\hline Unmarried/married & $4.2 \%(3.1-5.2)$ & 1.00 & 1.00 & 3678,3564 \\
\hline Divorced/widowed & $8.8 \%(4.2-13.3)$ & $2.21(1.21-4.04)$ & $1.79(1.08-2.97)$ & 52,41 \\
\hline Location of residence & - & $p=0.10$ & - & - \\
\hline Rural & $3.2 \%(2.0-4.5)$ & 1.00 & - & 1898,1553 \\
\hline Urban & $5.0 \%(3.5-6.4)$ & $1.56(0.92-2.64)$ & - & 1832, 2052 \\
\hline Smoking & - & $p=0.47$ & - & - \\
\hline No & $4.2 \%(3.2-5.3)$ & 1.00 & - & 3660,3551 \\
\hline Yes & $2.4 \%(0.0-6.2)$ & $0.56(0.12-2.70)$ & - & 70,54 \\
\hline Domestic violence from husband & - & $p=0.63$ & - & \\
\hline No & $4.1 \%(2.9-5.3)$ & 1.00 & - & 3406, 3141 \\
\hline Yes & $4.7 \%(2.6-6.8)$ & $1.15(0.67-1.97)$ & - & 195,176 \\
\hline Transfusion history & & $p=0.12$ & - & - \\
\hline No & $4.3 \%(3.3-5.4)$ & 1.00 & - & 3533,3398 \\
\hline Yes & $2.7 \%(0.7-4.7)$ & $0.61(0.33-1.14)$ & - & 197, 207 \\
\hline Having a tattoo & - & $p=0.04$ & $p=0.04$ & - \\
\hline No & $4.1 \%(3.1-5.2)$ & 1.00 & 1.00 & 3684,3569 \\
\hline Yes & $11.9 \%(0.9-22.9)$ & $3.14(1.07-9.18)$ & $2.89(1.07-7.84)$ & 46,36 \\
\hline Quality of sex activity & - & $p<0.01$ & $p<0.01$ & - \\
\hline Satisfied & $3.9 \%(2.8-5.0)$ & 1.00 & 1.00 & 3510, 3389 \\
\hline Dissatisfied & $8.5 \%(4.9-12.1)$ & $2.26(1.35-3.79)$ & $2.12(1.24-3.63)$ & 220,216 \\
\hline Extramarital sex & & $p=0.68$ & - & - \\
\hline No & $4.1 \%(2.8-5.4)$ & 1.00 & - & 3471,3197 \\
\hline Yes & $5.1 \%(1.0-9.1)$ & $1.24(0.44-3.50)$ & - & 130,121 \\
\hline Number of sex partners & - & $p=0.07$ & $p=0.15$ & - \\
\hline$<2$ & $4.1 \%(3.1-5.0)$ & 1.00 & 1.00 & 3617,3461 \\
\hline$\geq 2$ & $8.0 \%(1.7-14.2)$ & $2.05(0.95-4.44)$ & $2.17(0.76-6.23)$ & 113,144 \\
\hline Commercial sex & - & $p=0.86$ & - & \\
\hline No & $4.2 \%(3.2-5.2)$ & 1.00 & - & 3688,3572 \\
\hline Yes & $4.6 \%$ (0.0-9.8) & $1.09(0.41-2.91)$ & - & 42,33 \\
\hline
\end{tabular}

"Times of drunk in the past year" was not presented in the table because $91 \%$ of participants did not drink in the past year

$\mathrm{Cl}$ confidence interval, $O R$ odds ratio

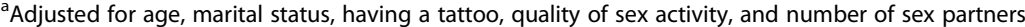

${ }^{\mathrm{b}}$ Denominator was participants with sex experience and a blood test result 
Compared with the two previous population-based HSV-2 seroprevalence surveys conducted in Zhengjiang and Shanghai, we found a spatial heterogeneity of HSV-2 distribution in China [9, 10]. The unweighted seroprevalence of HSV-2 was 13.5\% (95\% CI, 11.8-15.2) among the general population 15-49 years of age in Zhejiang in 2006 [9]. In our study, seroprevalence of HSV-2 among residents $18-49$ years of age $(3.4,95 \%$ CI, 2.2-4.7) was about one quarter of those in Zhejiang. For female residents 18-65 years of age in Shanghai, the unweighted seroprevalence of HSV-2 was $15.3 \%$ (95\% CI, 12.4-18.2) in 2011, which was about 2.6 times higher than those in females $18-49$ years of age in our study [10]. Both Zhejiang and Shanghai were located in southeastern coastal China. The high HSV-2 seroprevalence in the two regions may be due to large number of migrants. It is possible that migrants who had high-risk behaviors may spread STIs to the general population when moving from one place to another [15]. Therefore, HSV-2 control programs in China should be based on geographical regions.

We also compared the results of this study with other HSV-2 seroprevalence studies in American or European countries. HSV-2 infection is prevalent in 12.1\% (95\% CI, 9.7-15.0) of adults 14-49 years of age in the USA in 2015-2016, which is $>3$ times what we observed [16]. Another national population-based survey conducted in Peru showed that the HSV-2 seroprevalence was $10.0 \%$ (95\% CI, 9.6-10.4) and 17.4\% (95\% CI, 16.9-17.9) for sexually experienced males and females [13]. Balaeva $\mathrm{T}$ et al. performed a study of 1243 adults aged 18-39 years in Russia, which reported a HSV-2 seroprevalence of 18.8\% (95\% CI, 16.8-21.1) [3]. A fourth study conducted by Woestenberg PJ in the Netherlands in 2006-2007 showed that the HSV-2 seroprevalence of general Dutch population was $6.0 \%$ (95\% CI, 4.8-7.2) [17]. Compared the results of these surveys, we found a approximate 3 to $16 \%$ lower HSV-2 seroprevalence in our study. However, despite lower seroprevalence, the number of infected cases was substantial due to large population size of Shandong.

Most studies, including the current study, demonstrated that having multiple sex partners is associated with HSV-2 infection $[3,18-20]$. The findings of the current study indicated that risk for HSV-2 infection among males with $>2$ sex partners was 3 times as high as those with $<2$ sex partners in the past year. The number of lifetime sex partners was also associated with HSV-2 infection for females, although the strength of the association was weak. Extramarital or commercial sexual behaviors increased the number of sex partners for males and increased the risk of HSV-2 infection in the current study. Thus, males who have multiple sex partners were suggested to be tested for HSV-2 infection regularly.
Having a tattoo has been identified to be associated with $\mathrm{HIV}$, hepatitis $\mathrm{C}$ virus (HCV), and HSV-2 infections $[18,21,22]$. The current study showed that female residents who had a tattoo had a risk for HSV-2 infection that was $\sim 3$ times higher than those who did not have a tattoo. Tattooing is a way for people to express liberal attitudes towards life and sexuality [23]. Having a tattoo has been identified to be associated with being sexually active, early sexual initiation and a higher number of lifetime sexual partners, which increase the risk of STIs infection $[24,25]$. We estimated that nearly $1 \%$ of female residents $18-49$ years of age had a tattoo. Thus, this small percentage of high-risk individuals should be given greater emphasis when designing a HSV-2 control strategy.

Our study suggested that females who were divorced or widowed had a higher probability of HSV-2 infection. Several other surveys have also shown the same relationship between marital status and HSV-2 infection, particularly for females [3, 26, 27]. A study from Tanzania showed that females who were divorced or widowed may engage with multiple sex partners due to relative personal freedom and in an attempt to establish new relationships [27]. Another study from Kenya inferred that some of such females may experience significant pressure due to childrearing and few skills to earn money, thus some of them may resort to transactional sex [26]. However, the reason why females who were divorced or widowed had a relatively higher seroprevalence of HSV2 infection in Shandong still need further research.

Data collected in this study indicated that females with a poor quality of sex activity area high-risk population for infection with HSV-2. Researchers from Iran have reported that a lower level of sexual satisfaction can decrease the quality of marital life and increase the divorce rate [28]. Another study from Kenya showed an association between poor sexual satisfaction and extramarital partnerships [29]. Indeed, we have discussed that individuals who are divorced or have extramarital partnerships usually have multiple sex partners, which increases the risk to be infected with HSV-2. On the other hand, those women may be transmitted by their husbands who may engage in extramarital sexual behaviors due to dissatisfaction in couple's sex activity. We advised that females with a poor quality of sex activity to tested HSV-2 infection regularly.

There were several limitations in our study. First, individuals who migrated to their current residence and lived there for $>6$ months were hard to completely registered and sampled. Thus, the seroprevalence of HSV-2 may be underestimated because migrants were identified as high risk population of STIs infection [30]. Second, seroprevalence of HSV-2 among individuals less than 18 year of age and older than 49 years of age was not estimated in this study. Further investigation exploring 
seroprevalence of HSV-2 as well as other STIs among these people is recommended. Third, the sample size was relatively small for a few of sub-groups, such as 1824 year old group, which resulted in large 95\% CI and added some uncertainty to the estimates.

\section{Conclusions}

This study showed a relatively low burden of HSV-2 (seroprevalence: $3.4 \%$ ) in Shandong province, China compared with the seroprevalence reported in many other provinces and countries, including European countries and the Americas. The design and delivery of HSV-2 prevention and control intervention in Shandong should focus on eastern, urban and female residents, and pay more attention to individuals with identified associated factors.

\section{Abbreviations}

Cl: Confidence interval; ELISA: Enzyme-linked immune sorbent assay; HCV: Hepatitis C virus; HSV-2: Herpes simplex virus type-2; OD: Optical density; OR: Odds ratio; PPS: Probability proportionate to size sampling; PSU: Primary sampling unit; STIs: Sexually transmitted infections; VIF: Variance inflation factor

\section{Acknowledgments \\ The authors thank the 12 implementation partners in our survey: Station of Dermatology and Venereology in Ju county, Junan county, Qingzhou county-level city, Liaocheng municipality, Tengzhou county-level city, Qixia county-level city, Zhucheng county-level city and Linqu county, Center for Disease Control and Prevention in Chengyang District and Zoucheng county-level city, Wendeng District Hospital for Skin Disease, Zouping County Hospital of Traditional Chinese Medicine. We thank International Science Editing (http://www.internationalscienceediting.com) and Beng Tin Goh from the Royal London Hospital for editing this manuscript. The authors thank all} men and women who participated in this study.

\section{Funding}

This study was supported by the National Key Research and Development Program of China (2016YFE0201500), the Innovation Project of Shandong Academy of Medical Sciences and the Syphilis and Other Sexually Transmitted Diseases Control Research in Shandong. The funders had no roles in the design of the study, or the collection, analysis and interpretation of data, or writing the manuscript.

\section{Availability of data and materials}

The datasets used in the current study are not publicly available to maintain the privacy and confidentiality of the participants but are available from the corresponding author on reasonable request.

\section{Authors' contributions}

FZ conceived the study. FZ, AX, JL, DL, HL and PH contributed to the design of the study. PH, FL, ZL, LS, XF, ZC, TC, HW, BZ, CW, YS, GN, YZ, FF, XL, XW, $\mathrm{HZ}$ and DL performed the fieldwork and data collection. $L S, X F, Q P, G Y, Z M$ and FB undertook the laboratory analysis of the samples. PH conducted statistical data analysis. PH drafted the manuscript with intellectual contributions from all other authors. FZ, AX, JL, DL and HL critically revised the manuscript. All authors interpreted the data, reviewed and approved the final manuscript.

\section{Ethics approval and consent to participate}

This study was conducted in conformity to the ethical principles stated in the Helsinki Declaration. This study was reviewed and approved by the Ethics Committee of Shandong Provincial Institute of Dermatology and Venereology (approval number: 2016-04). The topic of the questionnaires was related to sex. Participants may refuse to answer sensitive questions or provide untruthful information if they signed informed consent. In order to obtain accurate information, oral informed consent instead of written consent was obtained from participants before each interview. This procedure was approved by the ethics committee.

\section{Consent for publication}

Not applicable.

\section{Competing interests}

The authors declare that they have no competing interests.

\section{Publisher's Note}

Springer Nature remains neutral with regard to jurisdictional claims in published maps and institutional affiliations.

\section{Author details \\ 'Shandong Provincial Hospital for Skin Disease, Shandong University, Jinan, China. ${ }^{2}$ Shandong Provincial Institute of Dermatology and Venereology, Shandong Academy of Medical Sciences, 27397 Jingshi Road, Jinan 250022, China. ${ }^{3}$ Department of Epidemiology, School of Public Health, Shandong University, Jinan, China. ${ }^{4}$ Shandong Provincial Key Laboratory for Dermatovenereology, Jinan, China. ${ }^{5}$ Shandong Center for Disease Control and Prevention, Jinan, China.}

Received: 23 December 2018 Accepted: 15 April 2019

Published online: 06 May 2019

\section{References}

1. World Health Organization. Report on global sexually transmitted infection surveillance. 2013. [http://apps.who.int/iris/bitstream/handle/10665/112922/ 9789241507400 eng.pdf]. Accessed 16 Mar 2016.

2. Looker KJ, Magaret AS, Turner KM, Vickerman P, Gottlieb SL, Newman LM. Global estimates of prevalent and incident herpes simplex virus type 2 infections in 2012. PLoS One. 2015;10:e114989.

3. Balaeva T, Grijbovski AM, Sidorenkov O, Samodova O, Firsova N, Sannikov A, et al. Seroprevalence and correlates of herpes simplex virus type 2 infection among young adults in Arkhangelsk, Northwest Russia: a population-based cross-sectional study. BMC Infect Dis. 2016;16:616.

4. Looker KJ, Garnett GP, Schmid GP. An estimate of the global prevalence and incidence of herpes simplex virus type 2 infection. Bull World Health Organ. 2008;86:805-12

5. Straface G, Selmin A, Zanardo V, De Santis M, Ercoli A, Scambia G. Herpes simplex virus infection in pregnancy. Infect Dis Obstet Gynecol. 2012;2012: 385697.

6. Freeman EE, Weiss HA, Glynn JR, Cross PL, Whitworth JA, Hayes RJ. Herpes simplex virus 2 infection increases HIV acquisition in men and women: systematic review and meta-analysis of longitudinal studies. AIDS. 2006;20: 73-83.

7. Yang S, Wu J, Ding C, Cui Y, Zhou Y, Li Y, et al. Epidemiological features of and changes in incidence of infectious diseases in China in the first decade after the SARS outbreak: an observational trend study. Lancet Infect Dis. 2017:17:716-25.

8. Sonnenberg P, Clifton S, Beddows S, Field N, Soldan K, Tanton C, et al. Prevalence, risk factors, and uptake of interventions for sexually transmitted infections in Britain: findings from the National Surveys of sexual attitudes and lifestyles (Natsal). Lancet. 2013;382:1795-806.

9. Lin H, He N, Su M, Feng J, Chen L, Gao M. Herpes simplex virus infections among rural residents in eastern China. BMC Infect Dis. 2011;11:69.

10. Zhang T, Yang Y, Yu F, Zhao Y, Lin F, Minhas V, et al. Kaposi's sarcoma associated herpesvirus infection among female sex workers and general population women in Shanghai, China: a cross-sectional study. BMC Infect Dis. 2014;14:58.

11. Zeng Y, Hesketh T. The effects of China's universal two-child policy. Lancet. 2016:388:1930-8.

12. Huai P, Li F, Li Z, Sun L, Fu X, Pan Q, et al. Prevalence, risk factors, and medical costs of chlamydia trachomatis infections in Shandong Province, China: a population-based, cross-sectional study. BMC Infect Dis. 2018;18:534.

13. Carcamo CP, Campos PE, Garcia PJ, Hughes JP, Garnett GP, Holmes KK. Prevalences of sexually transmitted infections in young adults and female sex workers in Peru: a national population-based survey. Lancet Infect Dis. 2012;12:765-73 
14. Chen S, Huai P, Wang X, Zhong J, Wang X, Wang K, et al. Risk factors for multidrug resistance among previously treated patients with tuberculosis in eastern China: a case-control study. Int J Infect Dis. 2013;17:e1116-20.

15. Xing H, Yu W, Li Y. Measuring and assessing HIV/AIDS stigma and discrimination among migrant workers in Zhejiang, China. BMC Public Health. 2016;16:845.

16. Beydoun HA, Dail J, Ugwu B, Boueiz A, Beydoun MA. Socio-demographic and behavioral correlates of herpes simplex virus type 1 and 2 infections and coinfections among adults in the USA. Int I Infect Dis. 2010;14:e154-60

17. Woestenberg PJ, Tjhie JH, de Melker HE, van der Klis FR, van Bergen JE, van der Sande MA, et al. Herpes simplex virus type 1 and type 2 in the Netherlands: seroprevalence, risk factors and changes during a 12-year period. BMC Infect Dis. 2016;16:364

18. Schneider JA, Lakshmi V, Dandona R, Kumar GA, Sudha T, Dandona L. Population-based seroprevalence of HSV-2 and syphilis in Andhra Pradesh state of India. BMC Infect Dis. 2010;10:59.

19. Fleming DT, McQuillan GM, Johnson RE, Nahmias AJ, Aral SO, Lee FK, et al. Herpes simplex virus type 2 in the United States, 1976 to 1994. N Engl J Med. 1997;337:1105-11.

20. Dan M, Sadan O, Glezerman M, Raveh D, Samra Z. Prevalence and risk factors for herpes simplex virus type 2 infection among pregnant women in Israel. Sex Transm Dis. 2003:30:835-8.

21. Zhang G, Wong M, Yi P, Xu J, Li B, Ding G, et al. HIV-1 and STls prevalence and risk factors of miners in mining districts of Yunnan, China. J Acquir Immune Defic Syndr. 2010;53:S54-60.

22. De Weggheleire A, An S, De Baetselier I, Soeung P, Keath H, So V, et al. A cross-sectional study of hepatitis $C$ among people living with HIV in Cambodia: prevalence, risk factors, and potential for targeted screening. PLoS One. 2017;12:e183530.

23. Kluger N. Epidemiology of tattoos in industrialized countries. Curr Probl Dermatol. 2015;48:6-20.

24. Nowosielski K, Sipinski A, Kuczerawy I, Kozlowska-Rup D, Skrzypulec-Plinta V. Tattoos, piercing, and sexual behaviors in young adults. J Sex Med. 2012;9: 2307-14.

25. Koch JR, Roberts AE, Armstrong ML, Owen DC. College students, tattoos, and sexual activity. Psychol Rep. 2005;97:887-90.

26. Otieno FO, Ndivo R, Oswago S, Pals S, Chen R, Thomas T, et al. Correlates of prevalent sexually transmitted infections among participants screened for an HIV incidence cohort study in Kisumu, Kenya. Int J STD AIDS. 2015;26: 225-37.

27. Kapiga SH, Ewings FM, Ao T, Chilongani J, Mongi A, Baisley K, et al. The epidemiology of HIV and HSV-2 infections among women participating in microbicide and vaccine feasibility studies in northern Tanzania. PLoS One. 2013;8:e68825

28. Shakerian A, Nazari AM, Masoomi M, Ebrahami P, Danai S. Inspecting the relationship between sexual satisfaction and marital problems of divorceasking women in Sanandaj City family courts. Procedia Soc Behav Sci. 2014; 114:327-33.

29. Kwena ZA, Shisanya CA, Bukusi EA, Turan JM, Dworkin SL, Rota GA, et al. Jaboya ("sex for fish"): a qualitative analysis of contextual risk factors for extramarital partnerships in the fishing communities in Western Kenya. Arch Sex Behav. 2017;46:1877-90.

30. Zou X, Chow EP, Zhao P, Xu Y, Ling L, Zhang L. Rural-to-urban migrants are at high risk of sexually transmitted and viral hepatitis infections in China: a systematic review and meta-analysis. BMC Infect Dis. 2014;14:490.

Ready to submit your research? Choose BMC and benefit from:

- fast, convenient online submission

- thorough peer review by experienced researchers in your field

- rapid publication on acceptance

- support for research data, including large and complex data types

- gold Open Access which fosters wider collaboration and increased citations

- maximum visibility for your research: over $100 \mathrm{M}$ website views per year

At $\mathrm{BMC}$, research is always in progress.

Learn more biomedcentral.com/submissions 